\title{
Oncology Unit
}

National Cancer Institute

\section{Source}

National Cancer Institute. Oncology Unit. NCI Thesaurus. Code C150764.

The part or unit of a hospital that provides specialized care for patients undergoing treatment for cancer. 